\title{
Diagnosis of ACOUSTiC Properties of RECYCLED MATERIALS FROM VEHICLES
}

\author{
Miroslav Badida, Lydia Sobotova, Kristian Pastor, Alzbeta Novakova, \\ Miroslava Badidova \& Veronika Gumanova
}
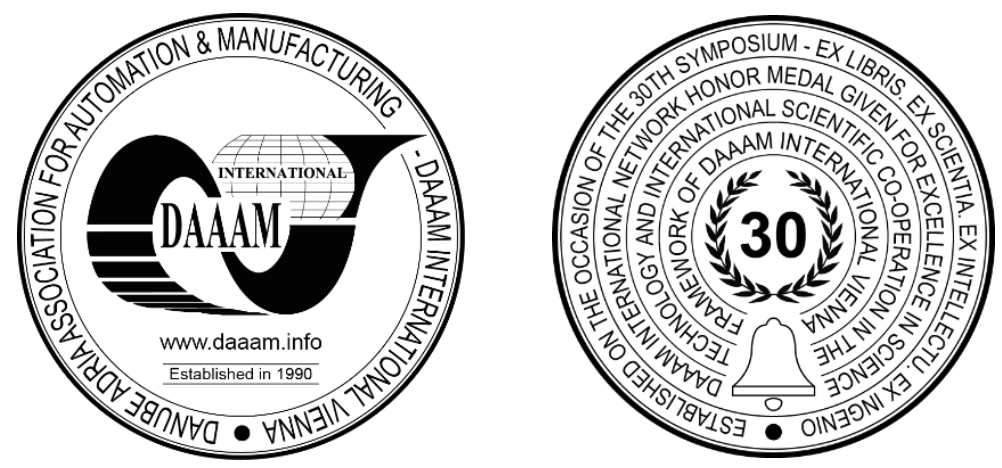

This Publication has to be referred as: Badida, M[iroslav]; Sobotova, L[ydia]; Pastor, K[ristian]; Novakova, A[lzbeta]; Badidova, M[iroslava] \& Gumanova, V[eronika] (2021). Diagnosis of Acoustic Properties of Recycled Materials from Vehicles, Proceedings of the 32nd DAAAM International Symposium, pp.0067-0074, B. Katalinic (Ed.), Published by DAAAM International, ISBN 978-3-902734-33-4, ISSN 1726-9679, Vienna, Austria

DOI: $10.2507 / 32$ nd.daaam.proceedings.010

\begin{abstract}
The aim of this paper is to present the results of the diagnosis of acoustic properties of selected single-layer and doublelayer, three-layer sandwich materials. The analysis was performed based on measurements using an impedance tube and the analysed acoustic properties were the sound absorption coefficient $\alpha(-)$ and the transmission attenuation (dB). Measurements were performed in the frequency range from $100 \mathrm{~Hz}$ to $6300 \mathrm{~Hz}$ for sample thicknesses from $10 \mathrm{~mm}$ up to $60 \mathrm{~mm}$. The results of the measurements were analysed and compared in terms of changes in the acoustic properties of the examined materials according to the changing thickness of these materials and the frequency band of the noise.
\end{abstract}

Keywords: Impedance tube; Sound absorption coefficient; Transmission attenuation; Recycled materials

\section{Introduction}

The acoustic properties of materials are playing an increasingly important role today. This is the reason why a number of new acoustically suitable materials with different sound insulation properties appear and develop almost every day. Recycled components from automobiles over their lifetime are often used to develop such materials. These materials are used for passive sound control in the design of car interiors, factories, workshops, residential buildings, noise barriers, etc. to prevent unwanted noise. The determination of acoustic properties is therefore extremely important. [1][2][4]

End-of-life vehicles represent a whole range of components (waste) of various material composition which should be further recovered. Focus is mainly on problematic materials from components, such as tyres, car seats, carpets, upholstery, airbags, glass, etc., and on the development of technologies and techniques for waste recovery into acoustic, thermal insulation, and other products.[4] The products from used car recycling that can be used for the production of sound absorbing elements are products from recycled tyres, car seats, seat covers, carpets and airbags. [4] 


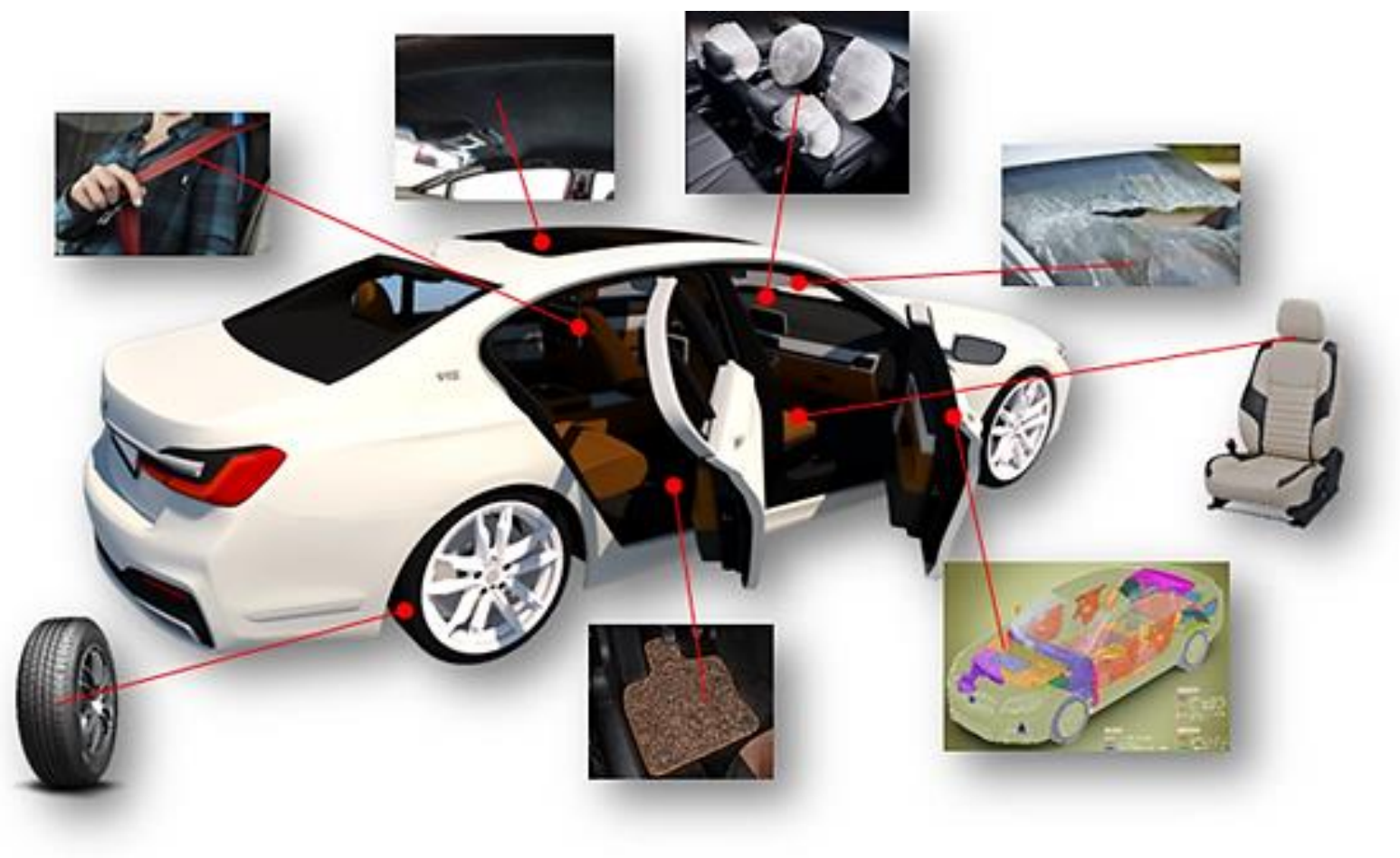

Fig. 1. Materials suitable for recycling

Research in this area seeks to control and minimize the sounds that occur in machines, cars, homes and other places. There are a large number of studies and research experiments that are trying to develop, discover new materials that can be used in various acoustic projects. For the analysis of these materials, sound absorption is one of the most important physical phenomena.[3]

Various synthetic materials have excellent acoustic properties, but their price and harmful effects on the environment must be taken into account. Bhingare N.H. describes the properties of natural fibres and waste (recycled) material. Natural materials are an effective alternative to synthetic ones due to their low cost and lower environmental impact. Waste material present in the environment, such as rubber crumbs from tires, waste wood etc., can be used with acoustic applications. This is emphasized in current research of natural fibrous materials, such as jute, kenaf, kapok and coconut fibres, fibres from palm and sugar cane, corn husk fibre and their acoustic performance is being researched. It was concluded that the properties of these natural materials can be effectively used for acoustic applications. The possibilities of using recycled natural or synthetic polymers from waste rubber in the production of acoustic materials for its good acoustic properties was studied by Xinwu X.[5][6]

This paper deals with the analysis of acoustic properties, namely the sound absorption coefficient $\alpha$ and the attenuation index R, for selected materials using an impedance tube. Several recycled materials from automobiles were selected, which were evaluated in terms of analysed acoustic properties in different thicknesses as separate single-layer materials, but also as sandwich two-layer and three-layer materials.

\section{Description of the measurement method and sample preparation}

The measurements were performed using a BSWA SW466 impedance tube in a configuration with two and four microphones using the transfer-function method according to the ISO 10534-2:1998 standard. The impedance tube has an advantage over other measurement methods due to its compactness, low cost and fast result. Compared to the reverberation chamber, the impedance tube requires significantly smaller samples of the tested material. A soundgenerating speaker is located on one side of the impedance tube and a removable sample holder with a fixed end is located at the other end. Microphones are placed between the speaker and the sample. Depending on the number of microphones used in the measurement, there are two, three or four microphone methods (Fig. 2).[1][2][7]

The sound absorption coefficient $(\alpha)$ is a dimensionless number ranging from $<0,1>$. The closer the value of the coefficient is to the number 1 , the better the sound absorption of the material. An impedance tube in a two-microphone configuration is used to measure the sound absorption factor of selected materials [8]. At one end of the tube is placed the sample to be examined and at the other end is a loudspeaker which is powered by a signal generator. The signal is then amplified in an amplifier. Two microphones of the same type are placed on the tube to measure acoustic pressures. Other components of the measuring technology are the MC3242 4-channel analyser for data collection, the PA50 measuring power amplifier from BSWA TECH and a computer equipped with VA-Lab4 software for information evaluation and tube control (Fig.3). 


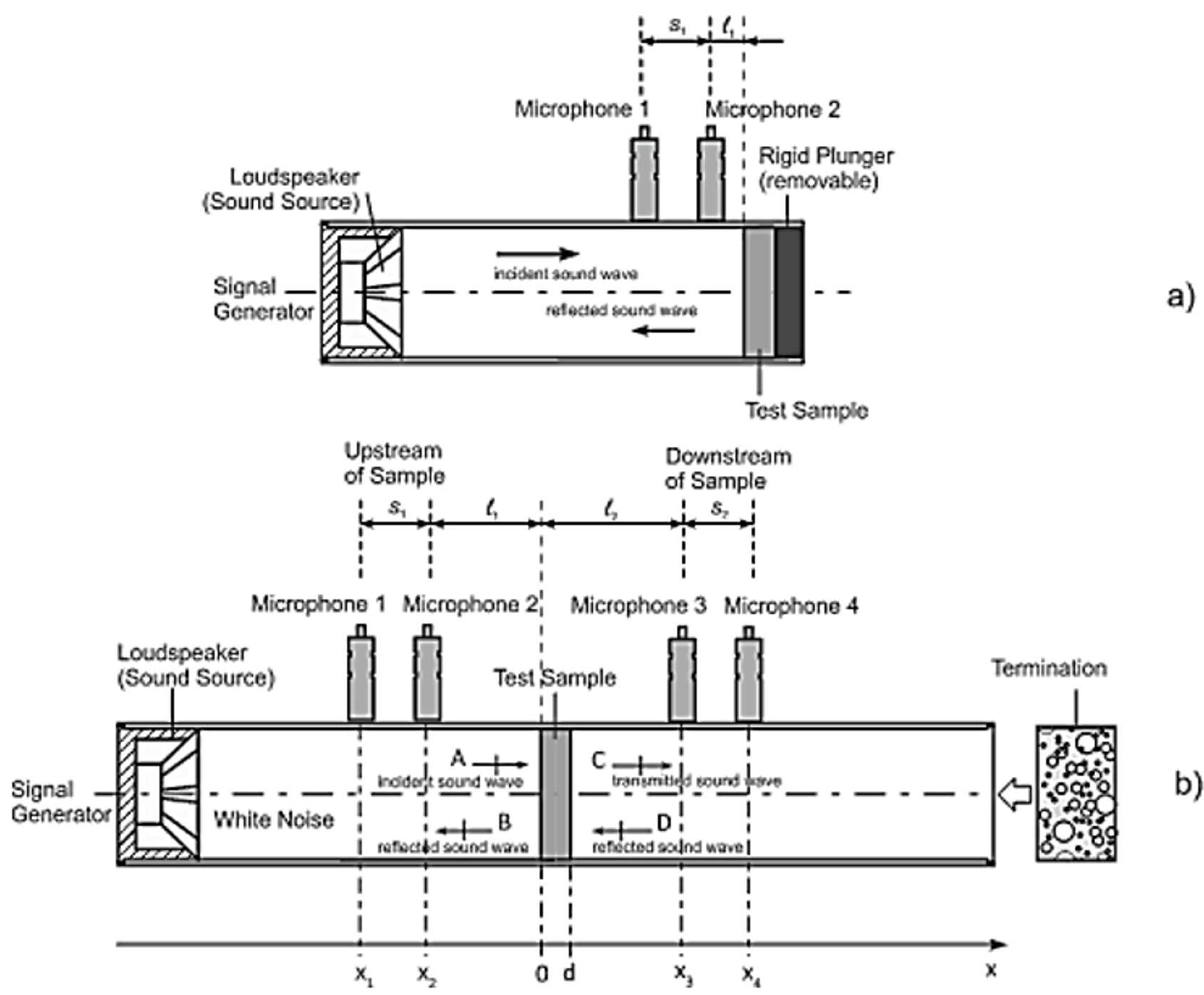

Fig. 2. Schematic of the SW466 impedance tube, a) method with two microphones, b) method with four microphones

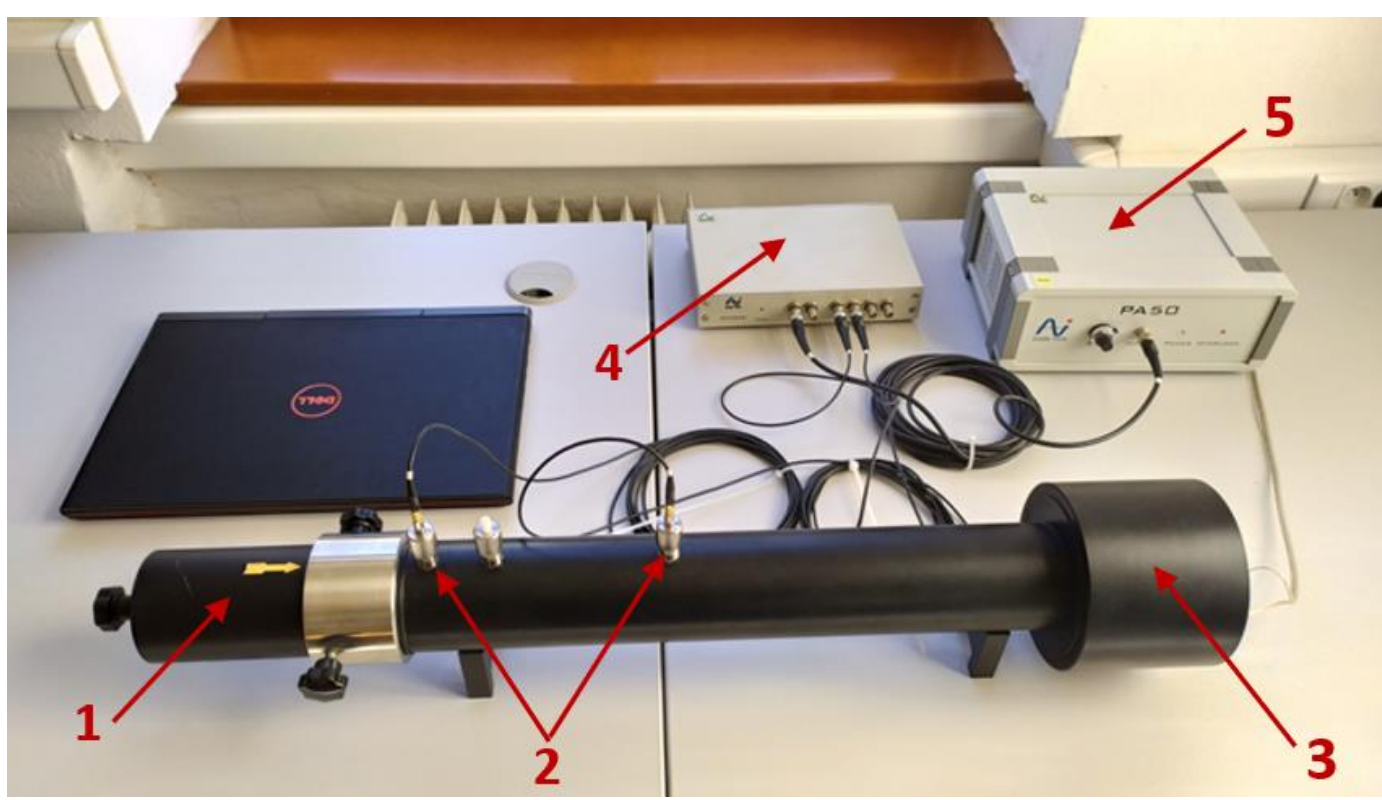

1 - Sample holder for measuring the sound absorption coefficient, 2 - Two microphones for measuring the sound absorption coefficient, 3 - Built-in speaker, 4 - Four-channel analyser, 5 - Power amplifier

Fig. 3. Measuring apparatus for measuring the sound absorption coefficient $\alpha(-)$ 
The attenuation index $\mathrm{R}$ is a value given in decibels $(\mathrm{dB})$ based on the ratio of the wave of sound incident on the front of the sound-absorbing material to the sound waves transmitted back. The attenuation index represents the damping properties of the material, which means that the higher the value of the attenuation index, the more attenuated the sound and the better the damping properties of the material. For the measurement of the attenuation index, either two reverberation rooms with a sample of material in the opening between the rooms or the impedance tube method are traditionally used.[9]

An impedance tube in a configuration with four microphones was used to measure the attenuation index of the examined materials. At one end of the tube there is a loudspeaker which is powered by a signal generator and the signal is subsequently amplified in an amplifier and at the other end of the tube in this case the sample holder is not connected as in sound absorption measurement but an extension tube is connected. The sample is located in the middle. Other components of the measuring technology are the MC3242 4-channel analyser for data collection, the PA50 measuring power amplifier from BSWA TECH and a computer equipped with VA-Lab4 software for information evaluation and tube control. (Fig.4)

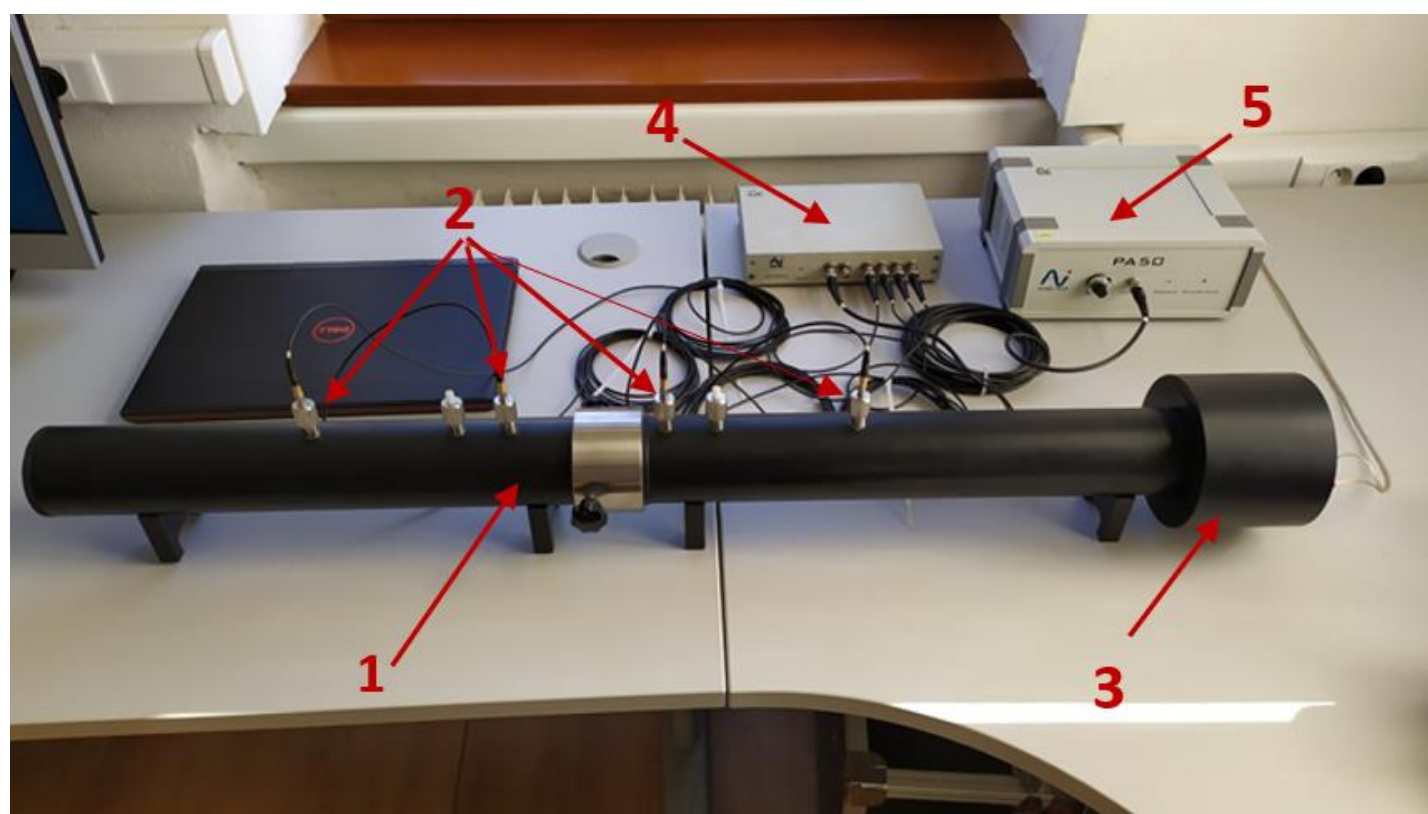

1 - Large extension tube for measuring attenuation index, 2 - Four microphones for measuring attenuation index, 3 Built-in speaker, 4 - Four-channel analyzer, 5 - Power amplifier

Fig. 4. Measuring apparatus for measuring The attenuation index R (dB)

Table 1 shows samples of materials used for the experiment. All samples had the same diameter, $30 \mathrm{~mm}$ or $60 \mathrm{~mm}$, which corresponds to the inner diameter of the tube. The thickness of the samples varied from $10 \mathrm{~mm}$ to $60 \mathrm{~mm}$.

The materials that were the subject of the research were:

- Nobasil

- Recycled rubber

- Ecomolitan

\begin{tabular}{|c|c|c|c|c|c|c|c|c|c|}
\hline Materiál & Photo of samples & $\begin{array}{c}\text { Thickness } \\
\text { of } \\
\text { material } \\
(\mathrm{mm})\end{array}$ & $\begin{array}{c}\text { Material } \\
\text { diameter } \\
(\mathbf{m m})\end{array}$ & \multicolumn{6}{|c|}{ Layer arrangement } \\
\hline \multirow{6}{*}{ Nobasil } & & 10 & \multirow{10}{*}{$\begin{array}{c}60 / 30 \\
\mathrm{~mm}\end{array}$} & & & & & & \\
\hline & & 20 & & & & & & & \\
\hline & & 30 & & & & & & & \\
\hline & & 40 & & & & & & & \\
\hline & & 50 & & & & & & & \\
\hline & & 60 & & 10 & 10 & 10 & 10 & 10 & 10 \\
\hline Ecomolitan & & 20 & & & & & & & \\
\hline & & 22 & & & & & & & \\
\hline & & 30 & & & & & & & \\
\hline & & 40 & & & & & & & \\
\hline
\end{tabular}




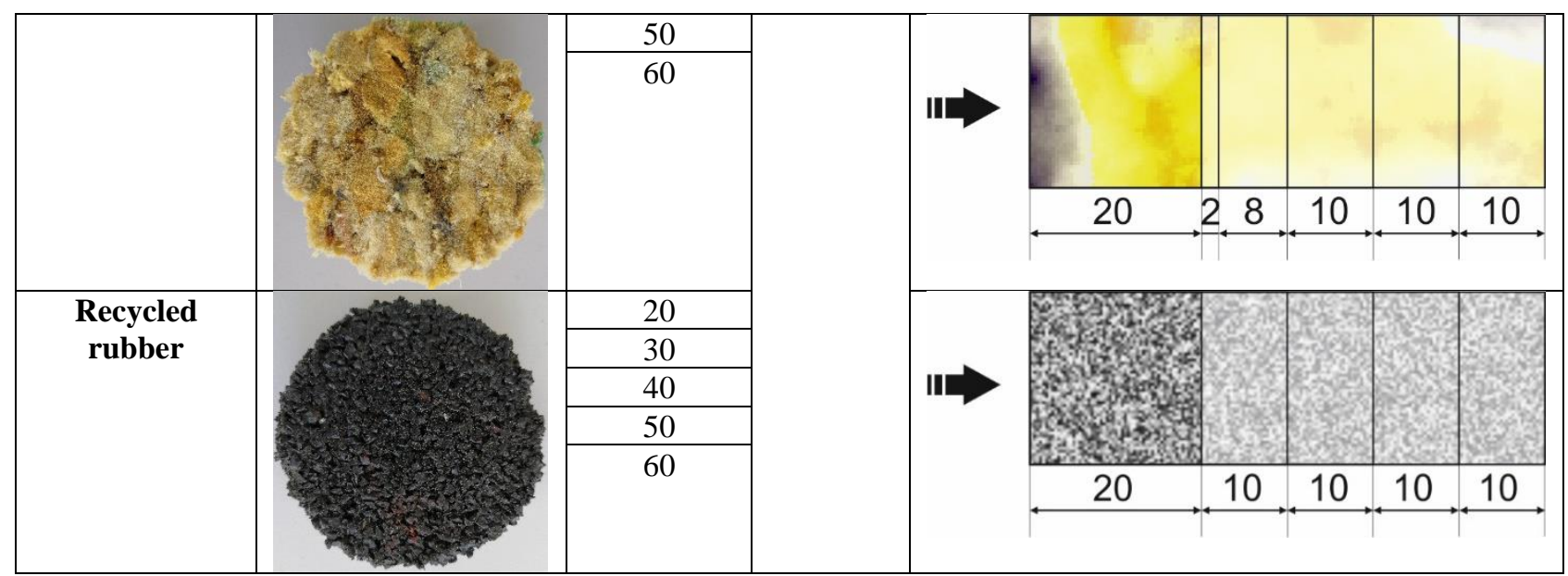

Table 1. Samples of the materials that were the subject of the research

\section{Processing of measurement results, comparison and evaluation}

The results (Fig. 5) show that at the sound absorption coefficient $\alpha$, the worst values are generally reached by the investigated materials at low frequencies in the range of approximately $100 \mathrm{~Hz}$ to $350 \mathrm{~Hz}$. The best values range in the wider frequency spectrum from $630 \mathrm{~Hz}$ up to $6300 \mathrm{~Hz}$. The best values are achieved for materials with thicknesses: Ecomolitan $30 \mathrm{~mm}$, Recycled rubber $20 \mathrm{~mm}$, Nobasil $30 \mathrm{~mm}$ and $40 \mathrm{~mm}$. It follows that thickness does not play a significant role in sound absorption, and that increasing the sound absorption coefficient is not directly proportional to the increasing thickness of the material.
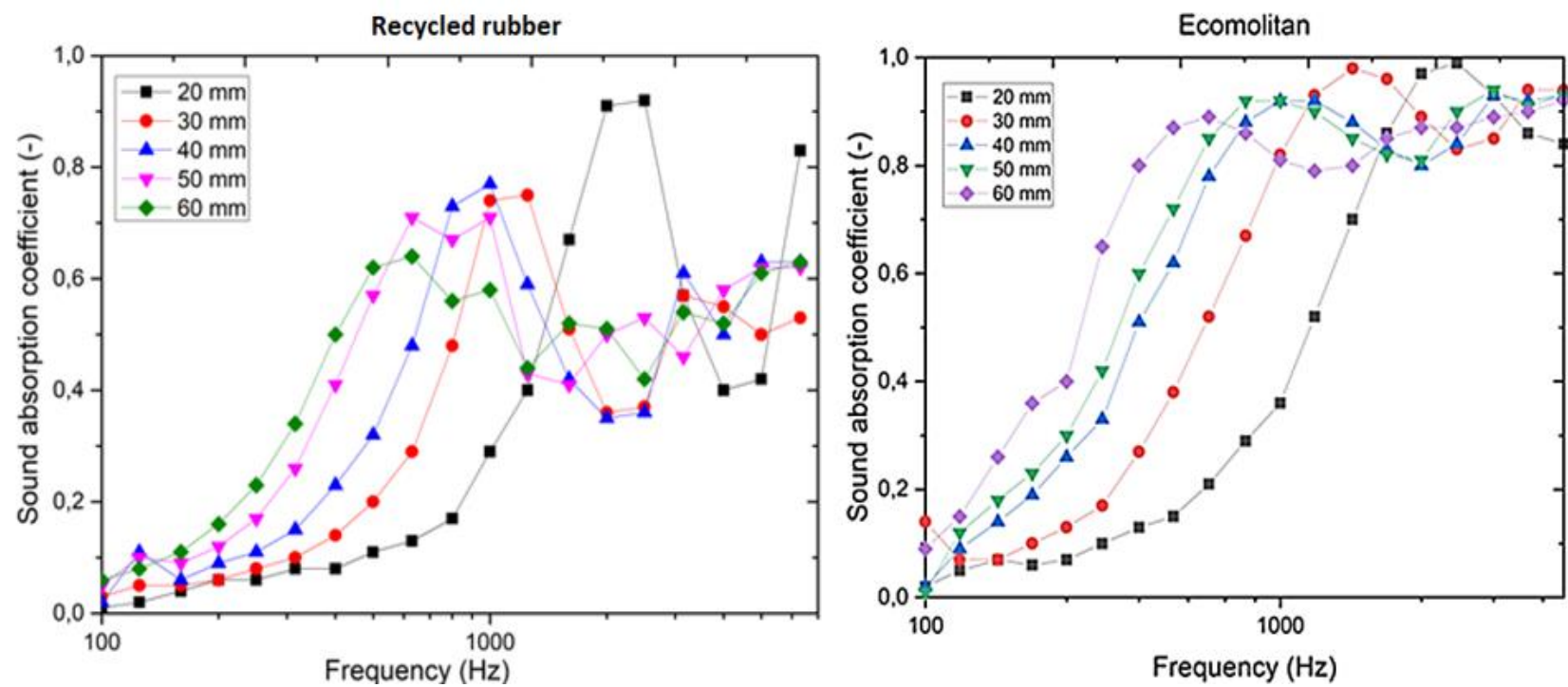

Fig. 5. Sound absorption coefficient values $\alpha$ for single layer materials

As with single-layer also with double-layer materials, it has been shown that the worst values of sound absorption are achieved by the investigated materials at lower frequencies, from $100 \mathrm{~Hz}$ to $125 \mathrm{~Hz}$. The best values, however, reach mainly in the middle frequency band from $315 \mathrm{~Hz}$ to $800 \mathrm{~Hz}$.

It can also be seen from the results that the values of the sound absorption coefficient are influenced not only by the composition of the sandwich material, i.e. what materials it is composed of, but also by the arrangement of these materials with respect to the direction of sound propagation. This can be seen, for example, in the sandwich material in the composition Recycled rubber + Nobasil (Fig. 6). In such an arrangement, when the Recycled Rubber is the first layer as opposed to the direction of sound propagation, the highest value of the sound absorption coefficient achieved was 0.75 at a frequency of $630 \mathrm{~Hz}$. In the reverse order of these materials, Nobasil + Recycled Rubber had the highest value of 0.86 at a frequency of $6300 \mathrm{~Hz}$. 


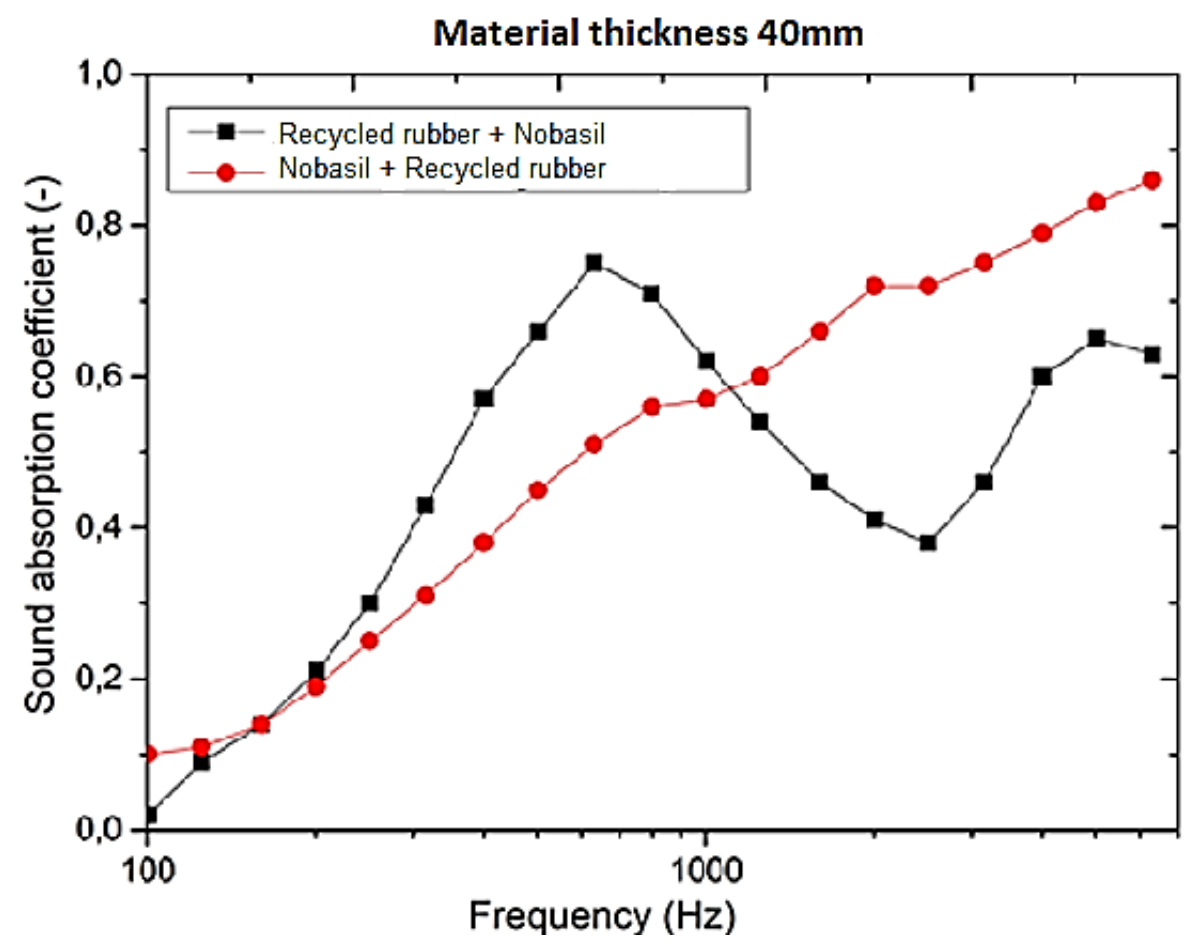

Fig. 6. Sound absorption coefficient values $\alpha$ for sandwich material Recycled rubber + Nobasil

As with the sound absorption coefficient $\alpha(-)$, the results of the Attenuation Index (dB) show that the investigated materials reach their best values at high sound frequencies, namely $5000-6300 \mathrm{~Hz}$. The results show that, in contrast to the sound absorption coefficient, the thickness of the material plays an important role in the attenuation index. Most materials achieved the best values at the largest sample thickness, i.e. $60 \mathrm{~mm}$. The graphs (Fig. 7) show the growth of the values, which is directly proportional to the increasing thickness of the material sample.
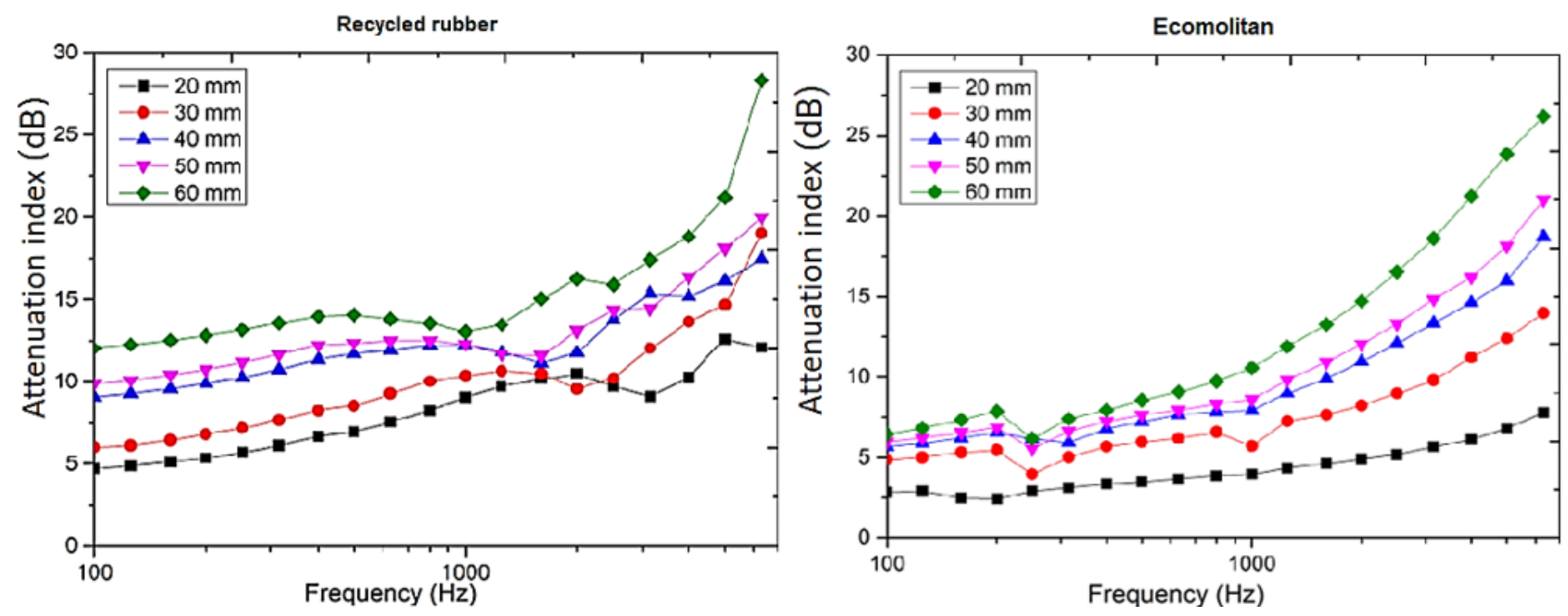

Fig. 7. Attenuation index values for single layer materials

It can also be seen in the graphs (Fig. 8) that, in contrast to the sound absorption in the attenuation index, the arrangement of the materials in the layers plays essentially no significant role. For the pair Recycled Rubber + Nobasil, slight differences in the frequency band from approximately $2000 \mathrm{~Hz}$ to $5000 \mathrm{~Hz}$ can be seen on the graph. For the other pairs, however, no difference in values is seen depending on the arrangement of the materials. It can also be seen that the two-layer material Recycled Rubber + Ecomolitan achieves in its two configuration variants the values of the attenuation index 17.98 and $17.56 \mathrm{~dB}$ at a sound frequency of $6300 \mathrm{~Hz}$ and a common thickness of $40 \mathrm{~mm}$. However, at the same thickness and frequency, these materials as single-layer values reach $17.49 \mathrm{~dB}$ for Recycled Rubber and even higher than the two-layer material for Ecomolitan at $18.71 \mathrm{~dB}$. 

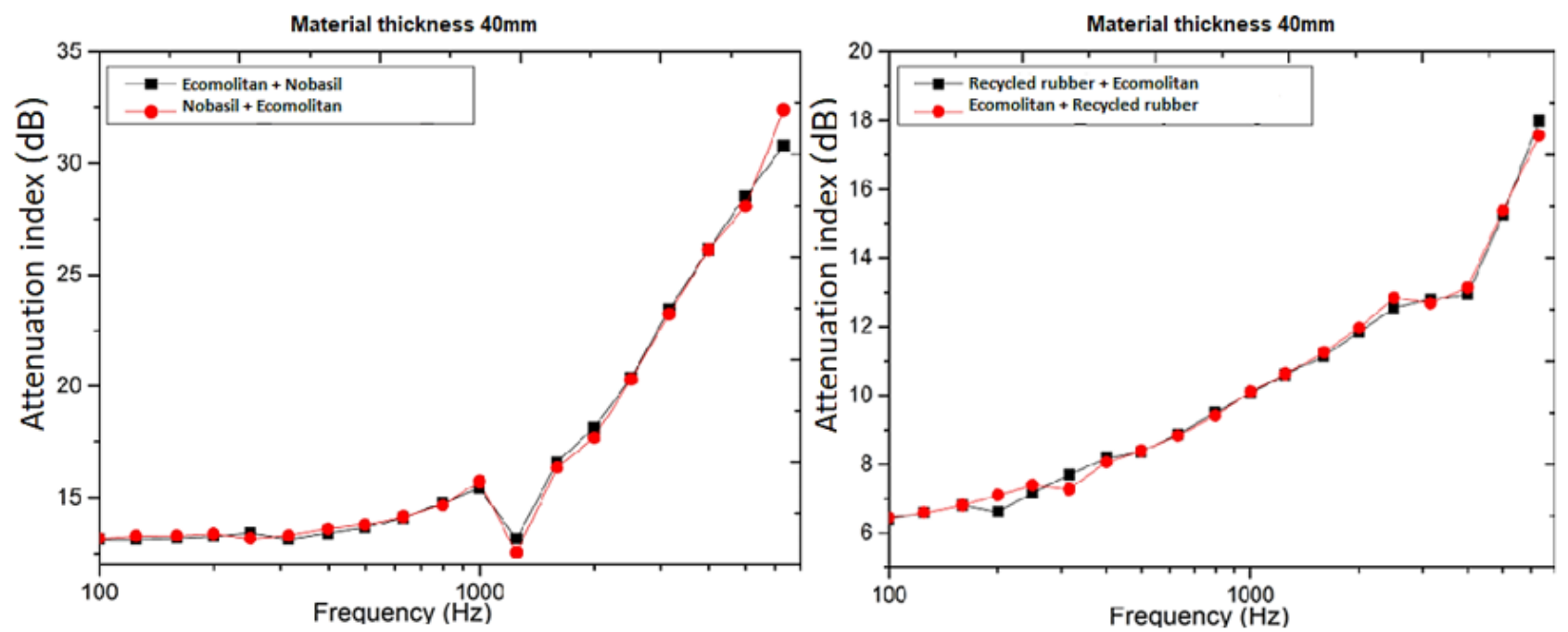

Fig. 8. Attenuation index values for sandwich materials

It can therefore be concluded that the arrangement of the materials in the case of two-layer sandwich materials does not play a major role in terms of transmission attenuation. Three-layer sandwich materials generally show better TL properties than two-layer materials. This, however, according to previous results, can be attributed more to the increasing thickness of the material than to its composition and the fact that it has three layers.

\section{Conclusion}

The aim of this research was to assess recycled materials from cars in terms of their acoustic properties. According to the measured results, it can be stated for the sound absorption coefficient $\alpha$ that the thickness of the analysed materials had no major effect on the value of the coefficient. The formation of sandwich materials, however, significantly affected the value of the coefficient and the properties of materials in different frequency bands. For sandwich materials, the arrangement of the materials with respect to the direction of noise propagation also played a role.

In the attenuation index $r$, in contrast to the sound absorption coefficient $\alpha$, the thickness of the material had a significant effect. The tables and graphs showed an increase in the value of the attenuation index, which was directly proportional to the increasing thickness of the material. Also, the formation of sandwich materials did not show any significant advantages in terms of attenuation index. In several cases, even when comparing sandwich and single-layer materials of the same thickness, single-layer materials showed higher transmission attenuation values than sandwich materials.

Based on these results, we can conclude that recycled materials from vehicles can be used as a sound insulation material after their lifetime. Also, by creating sandwich materials and their suitable distribution, we can very well manipulate the properties of these materials at different frequencies in terms of sound absorption and thus obtain a suitable insulating material for specific tasks. In the future, we would like to further investigate recycled materials from vehicles and assess their acoustic properties, assess their possible use in practice and also include other recycled materials in research.

\section{Acknowledgments}

This work was supported by the project titled KEGA No. KEGA 009TUKE-4/2021: Implementation of the latest knowledge from recycling technologies for material recovery of product components at the end of their life cycle

\section{References}

[1] Niresh, J.; et al. (2015). Review of acoustic characteristics of materials using impedance tube, ARPN Journal of Engineering and Applied Sciences, Vol. 10, No. 8, 2015, pp. 3319-3326, ISSN 1819-6608, Available from: http://www.arpnjournals.com/jeas/research_papers/rp_2015/jeas_0515_1928.pdf Accessed: 2021-09-07

[2] Arunkumar, B.; Jeyanthi, S. (2017). Design and analysis of impedance tube for sound absorption measurement, ARPN Journal of Engineering and Applied Sciences, Vol. 12, No. 5, 2017, pp. 1400-1405, ISSN 1819-6608, Available from: http://www.arpnjournals.org/jeas/research_papers/rp_2017/jeas_0317_5774.pdf Accessed: 202109-07

[3] Rosely, C.V.M.; Silva, R.H.A.; Linhares, T.M.; Rocha, C.M. (2012). The impedance tube construction and acoustic absorption study applied materials in side vehicles, 41st International Congress and Exposition on Noise Control Engineering 2012, Vol. 2, No.1, 2012, pp. 872-888, ISBN: 978-1-62748-560-9, Available from: 
https://www.researchgate.net/publication/289289454_The_impedance_tube_construction_and_acoustic_absorptio n_study_applied_materials_inside_vehicles Accessed: 2021-09-07

[4] Badida, M.; et al. (2021). Progresívne technológie zhodnocovania odpadov v automobilovom priemysle, Spektrum STU Bratislava, ISBN 978-80-553-3867-5

[5] Bhingare, N. H.; Prakash, S.; Jatti, V. S. (2019). A review on natural and waste material composite as acoustic material, Polym. Test., doi: 10.1016/j.polymertesting.2019.106142.

[6] Xu, X.; Wang, H.; Sun, Y.; Han, J.; Huang, R. (2018). Sound absorbing properties of perforated composite panels of recycled rubber, fiberboard sawdust, and high density polyethylene, Journal of Cleaner Production, vol. 187, 2018, doi: 10.1016/j.jclepro.2018.03.174.

[7] Labašová, E.; Ďuriš, R. (2019). Measurement of the acoustic absorption coefficient by impedance tube, Research Papers Faculty of Materials Science and Technology Slovak University of Technology, Vol. 27, No. 45, 2019 , pp. 94-101, ISSN 1338-0532, Available from: https://www.researchgate.net/publication/338031592_Measurement_of_the_Acoustic_Absorption_Coefficient_by _Impedance_Tube Accessed: 2021-09-07

[8] Měření zvukové pohltivosti materiálů, Laboratorní cvičení z Environmentální fyziky Fakulta technologická, UTB ve Zlíně, p. 8, Available from: http://ufmi.ft.utb.cz/texty/env_fyzika/EF_lab_02.pdf Accessed: 2021-09-07

[9] Badida, M.; Lumnitzer. E.; Bartko, L. (2011). Možnosti znižovania dopravného hluku. Elfa,s.r.o, Košice, 2011. ISBN 978-80-8086-181-0 